\title{
Remifentanil used as adjuvant in general anesthesia for spinal fusion does not exhibit acute opioid tolerance
}

\author{
Jong Hoon Yeom, Kyoung Hun Kim, Myong-Su Chon, Jangwon Byun, and Sang Yun Cho \\ Department of Anesthesiology and Pain Medicine, Hanyang University Guri Hospital, Hanyang University College of Medicine, Guri, \\ Korea
}

Background: Although acute tolerance to opioids, especially to remifentanil, has been demonstrated consistently in animal studies, the results of clinical trials in humans are controversial. The aim of this study was to determine whether intraoperative infusions of remifentanil used as an adjuvant in general anesthesia result in acute tolerance, an event manifested by increased postoperative pain and a higher opioid requirement than usual.

Methods: Sixty patients who underwent surgery under general anesthesia for spinal fusion were randomly assigned to receive sevoflurane-nitrous oxide-oxygen (group SO, $\mathrm{n}=20$ ), sevoflurane-remifentanil-nitrous oxide-oxygen (group $\mathrm{SR}, \mathrm{n}=20$ ), or propofol-remifentanil-oxygen (group PR, $\mathrm{n}=20$ ) in a double-blinded manner. All patients within 1 hour after induction received PCA (fentanyl $0.4 \mu \mathrm{g} / \mathrm{kg} / \mathrm{ml}$ and ondansetron $16 \mathrm{mg}$ ) administered intravenously at a basal infusion rate of $1 \mathrm{ml} / \mathrm{h}$, after being intravenously injected with a loading dose of fentanyl $(1 \mu \mathrm{g} / \mathrm{kg})$. Data for fentanyl requirement, verbal Numerical Rating Scale (NRS) pain score at rest, and presence of nausea or vomiting were collected at 1, 24, and 48 hours after surgery.

Results: We did not find any significant difference in postoperative PCA fentanyl requirements, NRS or side effects among the groups.

Conclusions: Remifentanil as an adjuvant to sevoflurane or propofol in general anesthesia for adults having surgery for spinal fusion does not appear to cause acute opioid tolerance or hyperalgesia in patients. However, further studies are needed to elucidate whether sevoflurane and propofol exert a clinically significant effect on opioidinduced tolerance or hyperalgesia and whether this effect is related to the age of the patient, the dose and duration of remifentanil given and the intensity of pain experienced postoperatively. (Korean J Anesthesiol 2012; 63: 103-107)

Key Words: Fentanyl, Patient-controlled analgesia, Remifentanil, Spinal fusion.

Received: October 20, 2011. Revised: 1st, January 14, 2012; 2nd, February 15, 2012; 3rd, March 1, 2012. Accepted: March 2, 2012.

Corresponding author: Jong Hoon Yeom, M.D., Ph.D., Department of Anesthesiology and Pain Medicine, Hanyang University Guri Hospital, 249-1, Gyomun-dong, Guri 471-701, Korea. Tel: 82-31-560-2390, Fax: 82-31-563-1731, E-mail: yeomjh@hanyang.ac.kr

(c) This is an open-access article distributed under the terms of the Creative Commons Attribution Non-Commercial License (http:// creativecommons.org/licenses/by-nc/3.0/), which permits unrestricted non-commercial use, distribution, and reproduction in any medium, provided the original work is properly cited. 


\section{Introduction}

Remifentanil, a short-acting opioid, is a predictably-acting anesthetic agent. It is associated with rapid recovery and its action is relatively independent of the dose, allowing infusion of large doses throughout surgery with little risk of postoperative delayed awakening or respiratory depression [1]. Continuous infusions of remifentanil have been used as the analgesic component of balanced general anesthesia, as an analgesic adjuvant in local and regional anesthesia [2,3], and as an analgesic in the immediate postoperative period before the transposition of patients to longer-acting analgesics $[2,4]$. However, an important concern about the intraoperative infusion of remifentanil is the possible development of acute opioid tolerance or hyperalgesia. Although acute tolerance to opioid has been demonstrated consistently in animal studies, the results of clinical trials in humans are controversial [5-8].

The aim of this study was to determine whether intraoperative infusion of remifentanil used as an adjuvant agent in general anesthesia results in acute tolerance as manifested by increased postoperative pain and a higher opioid requirement than usual.

\section{Materials and Methods}

Our study protocol received the approval of the human subjects ethical committee and all patients provided written informed consent. Sixty patients undergoing $1-2$ level posterior lumbar spinal fusion were enrolled. All of the patients were American Society of Anesthesiologists physical status classification 1 or 2 . Patients with a body mass index (BMI) $\geq 30$ were excluded from the study.

The day before surgery, patients were taught how to use the verbal Numerical Rating Scale (NRS) pain score at rest and the Patient-Controlled Analgesia (PCA) pump as well. They were also instructed to self-deliver analgesia by pressing the bolus button at any time they began to feel unendurable pain. The PCA pump (Accufuser PLUS ${ }_{\text {REF }}{ }^{\circledR}$, Woo Young Med, Korea) is an ambulatory elastometric infusion pump (total volume, $100 \mathrm{ml}$; basal flow rate, $1.0 \mathrm{ml} / \mathrm{h}$; bolus volume, $1.0 \mathrm{ml} /$ time; lockout time, $15 \mathrm{~min}$ ). A NRS of " 0 " was defined as no pain and a score of " 10 " was defined as the worst pain ever experienced by the patient.

Enrolled patients were not premedicated and patients who underwent surgery under general anesthesia were randomly allocated to three groups in a double-blinded manner. After standard monitoring (ECG, pulse oximeter, non-invasive blood pressure measurement), anesthesia was induced. Tracheal intubation for patients in group SO (sevoflurane-nitrous oxideoxygen) was performed under thiopental sodium $4-5 \mathrm{mg}$ / $\mathrm{kg}$, rocuronium $0.6-0.7 \mathrm{mg} / \mathrm{kg}$ and sevoflurane inhalation, and anesthesia was maintained with sevoflurane and $50 \%$ nitrous oxide in oxygen $(3 \mathrm{~L} / \mathrm{min})$. Tracheal intubation for patients in group SR (sevoflurane-remifentanil-nitrous oxideoxygen) was performed under thiopental sodium $4-5 \mathrm{mg} /$ $\mathrm{kg}$, rocuronium $0.6-0.7 \mathrm{mg} / \mathrm{kg}$, remifentanil infusion and sevoflurane inhalation, and anesthesia was maintained with sevoflurane, remifentani infusion and $50 \%$ nitrous oxide in oxygen $(3 \mathrm{~L} / \mathrm{min})$. Tracheal intubation for patients in group PR (propofol-remifentanil-oxygen) was performed under propopol and remifentanil infusion, rocuronium $0.6-0.7 \mathrm{mg} /$ $\mathrm{kg}$, and anesthesia was maintained with propofol, remifentanil and $50 \%$ oxygen $(3 \mathrm{~L} / \mathrm{min})$. All patients within 1 hour after induction intravenously received PCA (fentanyl $0.4 \mu \mathrm{g} / \mathrm{kg}$ / $\mathrm{ml}$ and ondansetron $16 \mathrm{mg}$ ) infused at a basal flow rate of $1 \mathrm{ml} / \mathrm{h}$, given after a loading dose of fentanyl $1 \mu \mathrm{g} / \mathrm{kg}$ was intravenously injected. Ramosetron $0.3 \mathrm{mg}$ was administered to all patients before wound closure to prevent postoperative nausea and vomiting (PONV). After surgery, patients were moved to the Post Anesthesia Care Unit (PACU) and were observed for at least 60 minutes. After the patients regained adequate cognitive function in the Post Anesthesia Care Unit (PACU), they were returned to their wards with the PCA pumps fully operational. No supplemental analgesia or sedation in the wards was administered to the patients during the first 48 hours after surgery. Data about the fentanyl requirement, the verbal Numerical Rating Scale (NRS) pain score at rest, and the incidence of nausea or vomiting (during the first hour, from 1 to 24 hours, and from 24 to 48 hours after surgery) were collected at 1, 24, and 48 hours after surgery. All studied solutions were prepared by anesthesiologists who were not involved in the patient's care. All the members involved in this study, including the enrolled patients and the anesthesiologist who delivered the PCA and evaluated the analgesic effect, were blinded to the study solutions. Remifentanil requirements were computed by dividing the total dose administered by the duration of anesthesia ( $\mathrm{min}$ ) and the body weight. Also, fentanyl requirements were computed by dividing the total dose administered by duration (h) and body weight.

Before the study, the sample size was determined by power analysis with a pilot study. The estimated sample size to detect a $30 \%$ difference of fentanyl requirement with mean $( \pm$ SD) differences among the groups, a power of $90 \%$, alpha $=0.05$, and drop rate $=0.1$ was 18 patients per group. Statistical analyses of data were performed using GraphPad Prism (Version 3.02, USA). Analysis of sex-related differences and the incidence of side effects was conducted with the chi-square test, and the physical status of the patient was analyzed with the KruskalWallis test. Other factors of the patients' parametric data except for remifentanil and the infusion rates of fentanyl were com- 
pared using one-way analysis of variance. Infusion rates of remifentanil were compared using the unpaired t-test. Results are expressed as the mean \pm SD unless otherwise specified. A probability $(\mathrm{P})$ value of less than 0.05 was considered to be statistically significant.

\section{Results}

None of the sixty patients enrolled in this study complained of or suffered from side effects that would have made them drop out of the study, and all of them completed it. There were no statistically significant differences in patient demographics, duration of surgery and anesthesia given, except for the intraoperative remifentanil infusion rate between group SR and PR (Table 1). We did not find any statistically significant differences in postoperative PCA fentanyl requirements (Table 2), NRS pain scores (Table 3) or side effects (Table 4) among the groups. In group SO, one patient complained of pruritus during the first 24 postoperative hours and was treated with chlorpheniramine maleate.

Table 1. Patient Demographics Data

\begin{tabular}{lccc}
\hline & $\begin{array}{c}\text { Group SO } \\
(\mathrm{n}=20)\end{array}$ & $\begin{array}{c}\text { Group SR } \\
(\mathrm{n}=20)\end{array}$ & $\begin{array}{c}\text { Group PR } \\
(\mathrm{n}=20)\end{array}$ \\
\hline Sex (M/F) & $6 / 14$ & $7 / 13$ & $5 / 15$ \\
Age (yr) & $58.8 \pm 8.9$ & $64.1 \pm 8.8$ & $63.7 \pm 12.2$ \\
Weight (kg) & $63.1 \pm 8.7$ & $60.2 \pm 9.9$ & $56.8 \pm 8.4$ \\
Height (cm) & $158.4 \pm 7.0$ & $157.4 \pm 8.8$ & $154.6 \pm 8.1$ \\
ASA status (I : II) & $2: 18$ & $3: 17$ & $0: 20$ \\
Body mass index & $24.9 \pm 2.5$ & $24.2 \pm 2.7$ & $23.7 \pm 2.3$ \\
Duration of surgery (h) & $3.0 \pm 0.6$ & $2.9 \pm 0.6$ & $3.1 \pm 0.4$ \\
Duration of anesthesia (h) & $3.8 \pm 0.7$ & $3.6 \pm 0.6$ & $3.9 \pm 0.5$ \\
Infusion rate of remifentanil & & $0.03 \pm 0.0$ & $0.16 \pm 0.0 *$ \\
$\quad(\mu \mathrm{g} / \mathrm{kg} /$ min) & & &
\end{tabular}

Values are mean \pm SD or number of patients. No statistically significant differences were noted among the groups except infusion rate of remifentanil. Group SO: sevoflurane-nitrous oxide-oxygen. Group SR: sevoflurane-remifentanil-nitrous oxide-oxygen. Group PR: propofol-remifentanil-oxygen. ${ }^{*} \mathrm{P}<0.05$ versus the group SR.

Table 2. Mean Infusion Rates of Fentanyl

\begin{tabular}{lccc}
\hline & $\begin{array}{c}\text { Group SO } \\
(\mathrm{n}=20)\end{array}$ & $\begin{array}{c}\text { Group SR } \\
(\mathrm{n}=20)\end{array}$ & $\begin{array}{c}\text { Group PR } \\
(\mathrm{n}=20)\end{array}$ \\
\hline First 1 h after surgery & $1.3 \pm 0.5$ & $1.4 \pm 0.5$ & $1.3 \pm 0.5$ \\
1 h till 24 h after surgery & $0.6 \pm 0.2$ & $0.6 \pm 0.1$ & $0.6 \pm 0.1$ \\
24 h till 48 h after surgery & $0.6 \pm 0.2$ & $0.5 \pm 0.1$ & $0.6 \pm 0.2$ \\
\hline
\end{tabular}

Values are mean \pm SD. Units of infusion rate: $\mu \mathrm{g} / \mathrm{kg} / \mathrm{h}$. No statistically significant differences were noted among the groups. Group SO: sevoflurane-nitrous oxide-oxygen. Group SR: sevoflurane-remifentanil-nitrous oxide-oxygen. Group PR: propofol-remifentaniloxygen.

\section{Discussion}

Remifentanil, a short-acting opioid, is a predictably-acting and rapid-recovery agent whose effect is relatively independent of the dose, allowing infusions of large doses throughout surgery with little risk of postoperative delayed awakening or respiratory depression [1]. The main problem of remifentanil-based anesthesia is the rapid disappearance of its analgesic effect after the cessation of infusion and the possible development of acute opioid tolerance. Because of this, a preventive analgesic approach involving intraoperative intravenous administration of longer-acting opioids is frequently used.

At present, the development of acute opioid tolerance in patients receiving remifentanil is under debate, and to this date remains controversial. Several studies deny the development of acute tolerance to remifentanil. Patients who self-controlled their analgesia using target-controlled infusions of alfentanil and remifentanil for postoperative analgesia after propofol and remifentanil anesthesia showed no evidence of tolerance to opioids [5]. Studies in patients who underwent elective gynecological non-laparoscopic surgery (average duration, 116 minutes) did not support the theory of the development of acute opioid tolerance after remifentanil-based anesthesia (mean remifentanil infusion rate $=0.23 \pm 0.10 \mu \mathrm{g} / \mathrm{kg} / \mathrm{min}$ ) when compared with sevoflurane-based anesthesia [6]. In a study in which a smalldose of remifentanil $(0.08 \mu \mathrm{g} / \mathrm{kg} / \mathrm{min})$ was continuously

Table 3. Numerical Rating Scale Pain Score at Rest

\begin{tabular}{lccc}
\hline & $\begin{array}{c}\text { Group SO } \\
(\mathrm{n}=20)\end{array}$ & $\begin{array}{c}\text { Group SR } \\
(\mathrm{n}=20)\end{array}$ & $\begin{array}{c}\text { Group PR } \\
(\mathrm{n}=20)\end{array}$ \\
\hline 1 h after surgery & $7.0 \pm 1.8$ & $5.7 \pm 2.0$ & $6.3 \pm 1.9$ \\
24 h after surgery & $4.6 \pm 2.1$ & $3.9 \pm 1.4$ & $5.0 \pm 2.0$ \\
48 h after surgery & $3.2 \pm 2.0$ & $2.8 \pm 1.2$ & $3.8 \pm 1.8$ \\
\hline
\end{tabular}

Values are mean \pm SD. A NRS pain score of 0 was defined as no pain anda score of 10 defined as the worst pain ever experienced. No statistically significant differences were noted among the groups. Group SO: sevoflurane-nitrous oxide-oxygen. Group SR: sevoflurane-remifentanil-nitrous oxide-oxygen. Group PR: propofolremifentanil-oxygen.

Table 4. Incidence of Nausea and Vomiting

\begin{tabular}{lccc}
\hline & $\begin{array}{c}\text { Group SO } \\
(\mathrm{n}=20)\end{array}$ & $\begin{array}{c}\text { Group SR } \\
(\mathrm{n}=20)\end{array}$ & $\begin{array}{c}\text { Group PR } \\
(\mathrm{n}=20)\end{array}$ \\
\hline First 1 h after surgery & 1 & 1 & 2 \\
1 h till 24 h after surgery & 1 & 3 & 2 \\
24 h till 48 h after surgery & 1 & 1 & 4 \\
\hline
\end{tabular}

No statistically significant differences were noted among the groups. Group SO: sevoflurane-nitrous oxide-oxygen. Group SR: sevoflurane-remifentanil-nitrous oxide-oxygen. Group PR: propofolremifentanil-oxygen. 
infused for 3 hours into volunteers, no development of acute opioid tolerance was observed [7]. In a recent case report, the development of acute opioid tolerance due to remifentanil was not encountered when it was co-administered with propofol or sevoflurane [8], just as in our study.

On the other hand, the phenomenon of rapid development of acute opioid tolerance is well-established in animals and humans and is more likely to occur with large doses of shortacting drugs. When remifentanil (infused at a constant rate of $0.3 \mu \mathrm{g} / \mathrm{kg} / \mathrm{min}$ ) was administered as a sole agent, acute opioid tolerance to both its analgesic and cardiorespiratory effects in a rabbit model developed within the first few hours [9]. Other studies have shown that acute opioid tolerance to analgesia during remifentanil infusion is profound and develops rapidly. Remifentanil, infused at a constant rate of $0.1 \mu \mathrm{g} / \mathrm{kg} / \mathrm{min}$ for 4 hours as a sole agent, resulted in a 3 -fold increase in pain intolerance in human volunteers [10]. There is also a study in which healthy volunteers who were infused solely with remifentanil for 90 minutes developed hyperalgesia within 30 minutes after stopping the infusion. In this study, the co-administration of NMDA-receptor antagonist S-ketamine is thought to prevent such hyperalgesia from occurring [11]. Intraoperative administration of remifentanil in relatively large doses $(0.25 \mu \mathrm{g} / \mathrm{kg} / \mathrm{min})$ when compared with small doses $(0.1 \mu \mathrm{g} / \mathrm{kg} / \mathrm{min})$ with desflurane inhalation resulted in acute opioid tolerance [12]. Large-dose remifentanil infusion $(0.5-0.8 \mu \mathrm{g} / \mathrm{kg} / \mathrm{min})$ for 218 minutes, when administered as a single agent, induced acute opioid tolerance following awake craniotomy in an adolescent [13]. Prolonged infusion (about 7-8 hours) of large-dose remifentanil $(0.28 \mu \mathrm{g} / \mathrm{kg} / \mathrm{min})$ for pediatric scoliosis surgery is associated with the development of clinically relevant acute opioid tolerance or hyperalgesia [14]. In our study, a small dose of remifentanil $(0.03 \mu \mathrm{g} / \mathrm{kg} / \mathrm{min}$ in group SR and $0.16 \mu \mathrm{g} / \mathrm{kg} /$ min in group PR) was given for a short period of time (averaging 216 minutes in group SR and 225 minutes in group PR) and was co-administered with sevoflurane or propofol.

The exact mechanism underlying the development of acute opioid tolerance and hyperalgesia is unknown, but the NMDA receptors are thought to play a major role in the development of acute opioid tolerance because remifentanil is known to stimulate the NMDA receptors [15-17], and remifentanilinduced hyperalgesia can be prevented by administering a low dose of ketamine, a typical NMDA antagonist [18]. In addition, prophylactic use of ketamine was reported to be effective in preventing post-anesthetic shivering induced by remifentanil [19].

Propofol, by noncompetitively acting at the NMDA receptors [20], may be able to attenuate the development of acute opioid tolerance or hyperalgesia following the administration of intraoperative opioid and thereby reduce postoperative analgesic requirement. In a recent case report, the development of acute tolerance to remifentanil was not encountered when the intraoperative opioid was co-administered with propofol or sevoflurane [8]. Also, postoperative morphine consumption for pediatric surgery was more than double of that for adult surgery [14]. Therefore, the possibility of age-related differences must be considered. In an animal model of rats, surgical pain could attenuate acute morphine tolerance [21]. A greater intensity of postoperative pain could have attenuated the development of opioid tolerance [14].

If a continuous infusion of remifentanil is likely to lead to the rapid development of acute tolerance, taking the above findings into consideration, factors which affect the development of acute tolerance appear to include the co-administration of sevorane or propofol, the dose and duration of the remifentanil infusion, the patient's age, and the intensity of the postoperative pain.

The dose of remifentanil infusion in our study was smaller than that in other studies investigating remifentanil-based anesthesia, because all patients in our study intra-operatively received intravenous PCA consisting of fentanyl $0.4 \mu \mathrm{g}$ / $\mathrm{kg} / \mathrm{ml}$ with a basal flow rate of $1 \mathrm{ml} / \mathrm{h}$ after being given an intravenous injection of a loading dose of fentanyl $(1 \mu \mathrm{g} / \mathrm{kg})$ within 1 hour after induction. The limitations of our study were that the duration of remifentanil infusion was relatively short (averaging 216 minutes in group SR and 225 minutes in group $\mathrm{PR})$, the dose of remifentanil was relatively small $(0.03 \mu \mathrm{g} / \mathrm{kg} /$ $\min$ in group SR and $0.16 \mu \mathrm{g} / \mathrm{kg} / \mathrm{min}$ in group PR), all patients were adults, and sevoflurane or propofol was co-administered with remifentanil, coincidently. Although the patients in our study showed no evidence of having developed acute opioid tolerance to remifentanil, we can not exclude the short duration of remifentanil infusion, the small-dose of remifentanil given to patients, or the co-administration of sevorane or propofol as confounding factors.

The incidence of PONV and pruritis was low in the present study when compared to other studies, and did not differ significantly among the groups. Given this relatively infrequent incidence, the study population in this study might have been too small to reveal differences in the incidence of PONV.

In conclusion, remifentanil used as an adjuvant in general anesthesia with sevoflurane or propofol in adults undergoing spinal fusion does not induce acute opioid tolerance or hyperalgesia in patients. However, further studies are needed to elucidate whether sevoflurane and propofol exert a clinically significant effect on opioid-induced tolerance and hyperalgesia, and to determine the effects that the age of the patient, the dose and duration of remifentanil given, and the intensity of post-operative pain have on opioid-induced tolerance and hyperalgesia following remifentanil administration. 


\section{References}

1. Thompson JP, Rowbotham DJ. Remifentanil--an opioid for the 21st century. Br J Anaesth 1996; 76: 341-3.

2. Burkle H, Dunbar S, Van Aken H. Remifentanil: a novel, shortacting, mu-opioid. Anesth Analg 1996; 83: 646-51.

3. Servin F, Desmonts JM, Watkins WD. Remifentanil as an analgesic adjunct in local/regional anesthesia and in monitored anesthesia care. Anesth Analg 1999; 89(4 Suppl): S28-32.

4. Albrecht S, Schuttler J, Yarmush J. Postoperative pain management after intraoperative remifentanil. Anesth Analg 1999; 89(4 Suppl): S40-5.

5. Schraag S, Checketts MR, Kenny GN. Lack of rapid development of opioid tolerance during alfentanil and remifentanil infusions for postoperative pain. Anesth Analg 1999; 89: 753-7.

6. Cortinez LI, Brandes V, Munoz HR, Guerrero ME, Mur M. No clinical evidence of acute opioid tolerance after remifentanil-based anaesthesia. Br J Anaesth 2001; 87: 866-9.

7. Gustorff B, Nahlik G, Hoerauf KH, Kress HG. The absence of acute tolerance during remifentanil infusion in volunteers. Anesth Analg 2002; 94: 1223-8.

8. Fodale V, Pratico C, Tescione M, Tanania S, Lucanto T, Santamaria LB. Evidence of acute tolerance to remifentanil in intensive care but not in anesthesia. J Clin Anesth 2006; 18: 293-6.

9. Hayashida M, Fukunaga A, Hanaoka K. Detection of acute tolerance to the analgesic and nonanalgesic effects of remifentanil infusion in a rabbit model. Anesth Analg 2003; 97: 1347-52.

10. Vinik HR, Kissin I. Rapid development of tolerance to analgesia during remifentanil infusion in humans. Anesth Analg 1998; 86: 1307-11.

11. Angst MS, Koppert W, Pahl I, Clark DJ, Schmelz M. Short-term infusion of the mu-opioid agonist remifentanil in humans causes hyperalgesia during withdrawal. Pain 2003; 106: 49-57.

12. Guignard B, Bossard AE, Coste C, Sessler DI, Lebrault C, Alfonsi P, et al. Acute opioid tolerance: intraoperative remifentanil increases postoperative pain and morphine requirement. Anesthesiology 2000; 93: 409-17.

13. Stricker PA, Kraemer FW, Ganesh A. Severe remifentanil-induced acute opioid tolerance following awake craniotomy in an adolescent. J Clin Anesth 2009; 21: 124-6.

14. Crawford MW, Hickey C, Zaarour C, Howard A, Naser B. Development of acute opioid tolerance during infusion of remifentanil for pediatric scoliosis surgery. Anesth Analg 2006; 102: 1662-7.

15. Dal D, Kose A, Honca M, Akinci SB, Basgul E, Aypar U. Efficacy of prophylactic ketamine in preventing postoperative shivering. Br J Anaesth 2005; 95: 189-92.

16. Honarmand A, Safavi MR. Comparison of prophylactic use of midazolam, ketamine, and ketamine plus midazolam for prevention of shivering during regional anaesthesia: a randomized double-blind placebo controlled trial. Br J Anaesth 2008; 101: 55762.

17. Nakasuji M, Nakamura M, Imanaka N, Tanaka M, Nomura M, Suh SH. Intraoperative high-dose remifentanil increases postanaesthetic shivering. Br J Anaesth 2010; 105: 162-7.

18. Joly V, Richebe P, Guignard B, Fletcher D, Maurette P, Sessler DI, et al. Remifentanil-induced postoperative hyperalgesia and its prevention with small-dose ketamine. Anesthesiology 2005; 103: 147-55.

19. Nakasuji M, Nakamura M, Imanaka N, Tanaka M, Nomura M, Suh SH. An intraoperative small dose of ketamine prevents remifentanil-induced postanesthetic shivering. Anesth Analg 2011; 113: 484-7.

20. Grasshoff C, Gillessen T. Effects of propofol on N-methyl-Daspartate receptor-mediated calcium increase in cultured rat cerebrocortical neurons. Eur J Anaesthesiol 2005; 22: 467-70.

21. Ho ST, Wang JJ, Liaw WJ, Lee HK, Lee SC. Surgical pain attenuates acute morphine tolerance in rats. Br J Anaesth 1999; 82: 112-6. 